\title{
Por que a elasticidade-preço das importações é baixa no Brasil? Evidências a partir das desagregações das importações por categorias de uso *
}

\author{
Cláudio Hamilton Matos dos Santos ** \\ André Cieplinski \\ Débora M. Pimentel ${ }^{* * * *}$ \\ Gustavo Bhering ${ }^{* * * * *}$
}

\begin{abstract}
Resumo
Estudos recentes indicam que a elasticidade-preço das importações brasileiras é baixa. Este trabalho procura racionalizar o referido resultado revisitando as estimativas das importações do país desagregadas por "categoria de uso". Os resultados reportados sugerem que a baixa elasticidade-preço das importações agregadas reflete fundamentalmente a baixa elasticidade-preço das importações de combustíveis, bens intermediários e de alguns tipos de serviços - notadamente, transporte, aluguel de equipamentos e pagamentos de royalties - produtos que, somados, respondem por pouco menos de dois terços do total importado. Isso ocorre porque vários desses produtos têm pouca ou nenhuma possibilidade de substituição por similares nacionais, devido principalmente a deficiências estruturais na oferta nacional.
\end{abstract}

Palavras-chave: Elasticidade-preço das importações; Importações brasileiras; Importações desagregadas; Categorias de uso; Brasil.

\section{Abstract \\ Why is the price elasticity of imports low in Brazil? Evidence from disaggregated imports}

Recent studies have pointed out to a low price elasticity of Brazilian imports. In this study we provide a rationale for this result by revisiting the behavior of imports disaggregated in seven different categories. According to the results reported in this paper, the low price elasticity of total imports reflects the low price elasticities of intermediate goods, oil and fuel, and services such as transportation, royalties, and rents paid on machinery and equipment - products which together amount to about two thirds of aggregate Brazilian imports. We find that several of these imports have low or null possibility of substitution for domestic products, due to structural deficiencies in Brazilian productive capacity.

Keywords: Price-elasticity of imports; Brazilian imports; Disaggregated imports; Imports categories; Brazil.

JEL F14, L16, F40.

* Artigo recebido em 8 de setembro de 2014 e aprovado em 25 de novembro de 2016.

** Técnico de Planejamento e Pesquisa do Instituto de Pesquisa Econômica Aplicada - IPEA, Rio de Janeiro, RJ, Brasil. E-mail: claudio.santos@ipea.gov.br.

*** Doutorando em Economia na Universidade de Siena (Unisi), Siena, Itália. E-mail: andrecieplinski@gmail.com

${ }^{* * * * *}$ Doutoranda em Economia no Instituto de Economia da Universidade Federal do Rio de Janeiro (UFRJ), Rio de Janeiro, RJ, Brasil. E-mail: deboramp@globo.com.

***** Doutorando em Economia no Instituto de Economia da Universidade Federal do Rio de Janeiro, Rio de Janeiro, RJ, Brasil. E-mail: gustavo.bhering@gmail.com. 


\section{Introdução}

Estudos recentes têm convergido para a visão de que a elasticidade-preço das importações brasileiras é baixa. Minella e Souza-Sobrinho (2009), por exemplo, apontam que uma desvalorização de $1 \%$ na taxa de câmbio real leva a uma redução de $0,17 \%$ no índice de volume das importações totais. Resultados semelhantes foram reportados também por Muinhos e Alves (2003) e Gouvea e Schettini (2011).

Este trabalho tem o objetivo de aprofundar as análises anteriores revisitando as estimativas das importações totais do país por "categoria de uso". Trata-se de um tema clássico, sem dúvida. A literatura de especificações econométricas da dinâmica das importações brasileiras é rica em análises desagregadas. Portugal (1992) e Carvalho e Parente (1999), por exemplo, estimaram especificações semelhantes às reportadas neste trabalho. Todavia, pouco se escreveu sobre o assunto nos últimos tempos $^{1}$ - talvez por conta da bonança externa que caracterizou a última década $-\mathrm{e}$ poucos duvidariam que muita coisa mudou na estrutura produtiva brasileira desde então.

A natureza periférica do capitalismo brasileiro continua a mesma, entretanto. Não surpreende, assim, que - tal como Tavares (1972) em sua clássica análise do processo de substituição de importações - argumentemos aqui que a baixa elasticidade-preço das importações totais reflete fundamentalmente deficiências da estrutura produtiva nacional.

A referida argumentação é construída em duas etapas. Primeiramente, os resultados econométricos reportados nesse trabalho sugerem que a baixa elasticidade-preço das importações agregadas reflete basicamente a baixa elasticidade-preço das importações de combustíveis, bens intermediários e alguns tipos de serviços - notadamente, transporte, aluguéis de equipamentos e pagamentos de royalties - produtos que, somados, respondem por pouco menos de dois terços das importações totais de bens e serviços do país.

Ora, a baixa substitutibilidade entre as importações de combustíveis e de serviços e a produção doméstica desses últimos é um fato estilizado clássico da dinâmica das importações brasileiras (e.g. Zini, 1988; Reis et al. 1999). Já a baixa substituição entre as importações de bens intermediários e a produção doméstica é um fenômeno mais recente - Portugal (1992) e Carvalho e Parente (1999), por exemplo, encontram elasticidades-preço próximas a ou maiores do que um, em valores absolutos, para estes bens e serviços. Mas esta mudança parece plausível à medida que se tem claro o segundo passo do argumento desse texto, qual seja, o fato de a maior parte destes bens intermediários serem hoje autopeças, fertilizantes,

(1) Sapienza (2007) é uma exceção a esta regra. Contudo, o autor essencialmente desconsidera a possibilidade de quebras estruturais nos dados. Daí, aparentemente, os resultados "contrários ao esperado pela teoria econômica" que reporta (ver seções 2 e 3 deste texto). 
outros compostos químicos e petroquímicos, e componentes eletrônicos. Setores, em suma, nos quais o país tem claros problemas de oferta.

Note-se que não atribuímos estas deficiências a um suposto processo de desindustrialização - em contraste, por exemplo, com Bresser-Pereira (2012) e Oreiro e Feijó (2010). Com efeito, os principais produtos deficitários na balança comercial brasileira são principalmente de alto conteúdo tecnológico e correspondem a cadeias produtivas que sequer foram efetivamente instaladas no âmbito nacional, como a química fina, microchips e semicondutores, ou a produtos inseridos nas cadeias globais de valor cujas importações e exportações dependem principalmente das estratégias de empresas transnacionais e da maneira como as empresas nacionais se inserem nestas cadeias (Gereffi et al., 2005).

O restante do texto está organizado em cinco seções. A seguir, na primeira seção, são apresentados os dados relativos à composição das importações brasileiras. A seção dois faz uma breve resenha da literatura empírica que trata da elasticidadepreço das importações. A terceira parte do texto expõe a metodologia empírica utilizada e está dividida entre os procedimentos econométricos adotados e a descrição das variáveis empregadas nos testes. Por fim, a quarta seção apresenta os resultados econométricos propriamente ditos enquanto a última os discute e apresenta nossas considerações finais.

\section{Descrição dos dados}

O presente estudo faz uso dos dados de importação de bens disponibilizados pela Funcex ${ }^{2}$ e das despesas com serviços do balanço de pagamentos, doravante denominadas importações de serviços. Além das importações agregadas, utiliza-se a desagregação tradicional dos bens em cinco categorias de uso, a saber: i) bens de consumo duráveis (BCD), ii) não duráveis (BCND), iii) intermediários (BI), iv) de capital (BK) e v) combustíveis e lubrificantes (C\&L); e duas classes de importações de serviços: vi) transportes, royalties e aluguel de equipamentos (Serv. TRA) e vii). outros serviços (Serv. Outros). Estas sete categorias incluem bens com características bastante distintas - notadamente no que tange a intensidade tecnológica e complexidade de seus respectivos processos produtivos.

O Gráfico 1 mostra uma composição relativamente estável das importações nominais totais entre 1996 e 2013. Os bens intermediários há tempos constituem a maior parcela das importações, somando em média $43 \%$ do total, seguidos pelos serviços com $24 \%$, bens de capital, $13 \%$, combustíveis e lubrificantes, $11 \%$, bens de consumo não duráveis $6 \%$ e duráveis com $3 \%$.

(2) Fundação Centro de Estudos do Comércio Exterior (www.funcex.org.br). 
Gráfico 1

Distribuição das importações agregadas (1996-2013)

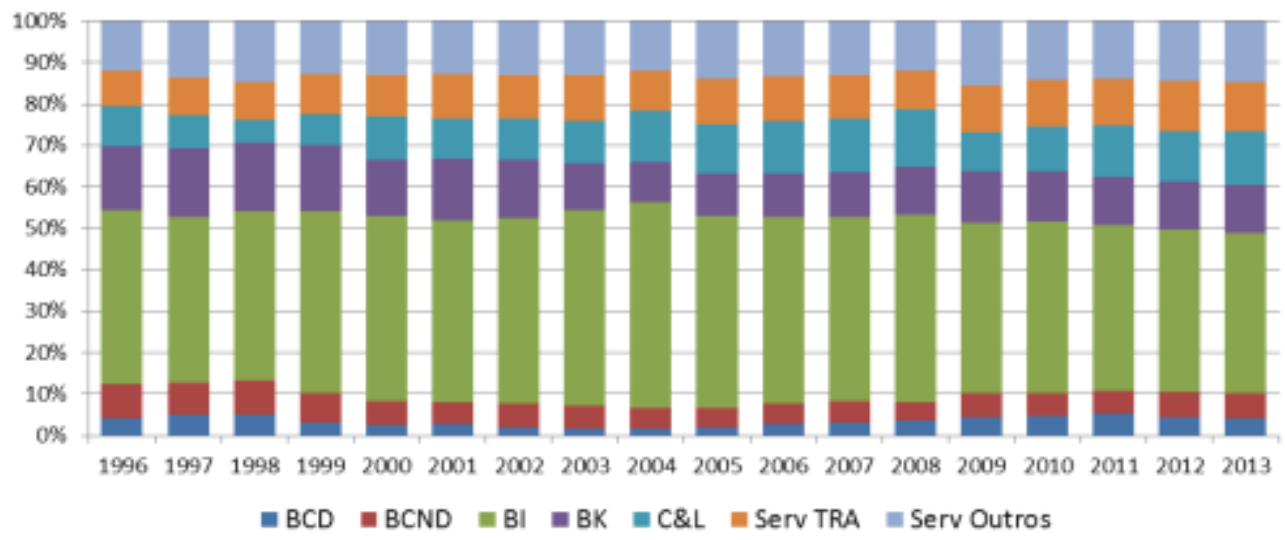

Nota: BCN: Bens de consumo duráveis, BCND: Bens de consumo não duráveis, BI: Bens intermediários, BK: Bens de capital, C\&L: Combustíveis e lubrificantes, Serv TRA: Serviços de transporte, pagamentos de royalties e aluguéis de equipamentos, Serv Outros: Demais serviços. Fonte: Elaboração com base nos dados da Funcex, BCB e IBGE.

Gráfico 2

Distribuição das Importações de Bens (1978-2013)

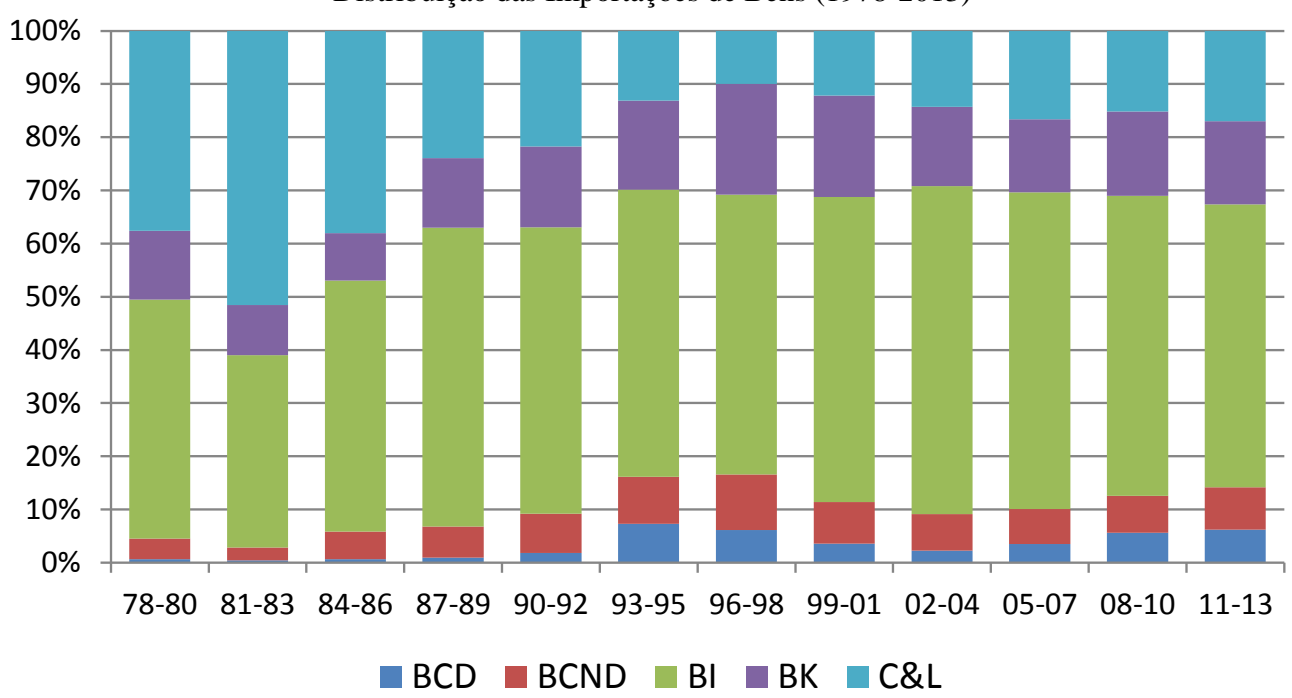

Nota: BCN: Bens de consumo duráveis, BCND: Bens de consumo não duráveis, BI: Bens Intermediários, BK: Bens de capital, C\&L: Combustíveis e lubrificantes.

Fonte: Elaboração com base nos dados da FUNCEX e IBGE

Mudanças na composição das importações de bens são mais evidentes quando se amplia o prazo da análise para o período 1978-2013. De fato, os dados demonstram uma notável redução das importações de combustíveis ao longo da década de 1980 e, em menor grau, na primeira metade dos 90. Esta mudança nas importações de petróleo está diretamente ligada às descobertas dos reservatórios 
offshore na Bacia de Campos. Apesar dos primeiros campos terem sido descobertos já no início da década de 1970, foi apenas a partir dos anos $80^{3}$ que se observou um aumento significativo na extração de óleo em território nacional.

Um olhar mais detalhado sobre as importações de serviços, por sua vez, evidencia o forte crescimento das despesas com aluguel de equipamentos, de aproximadamente 5\% em 1996 para 22\% em 2013, que reflete principalmente o aluguel de equipamentos de exploração "exportados" da Petrobras ${ }^{4}$. Ainda assim transportes e viagens internacionais seguem como os dois itens principais, somando em média $47 \%$ das importações de serviço.

\section{Gráfico 3}

Importações de Serviços (1996-2013)

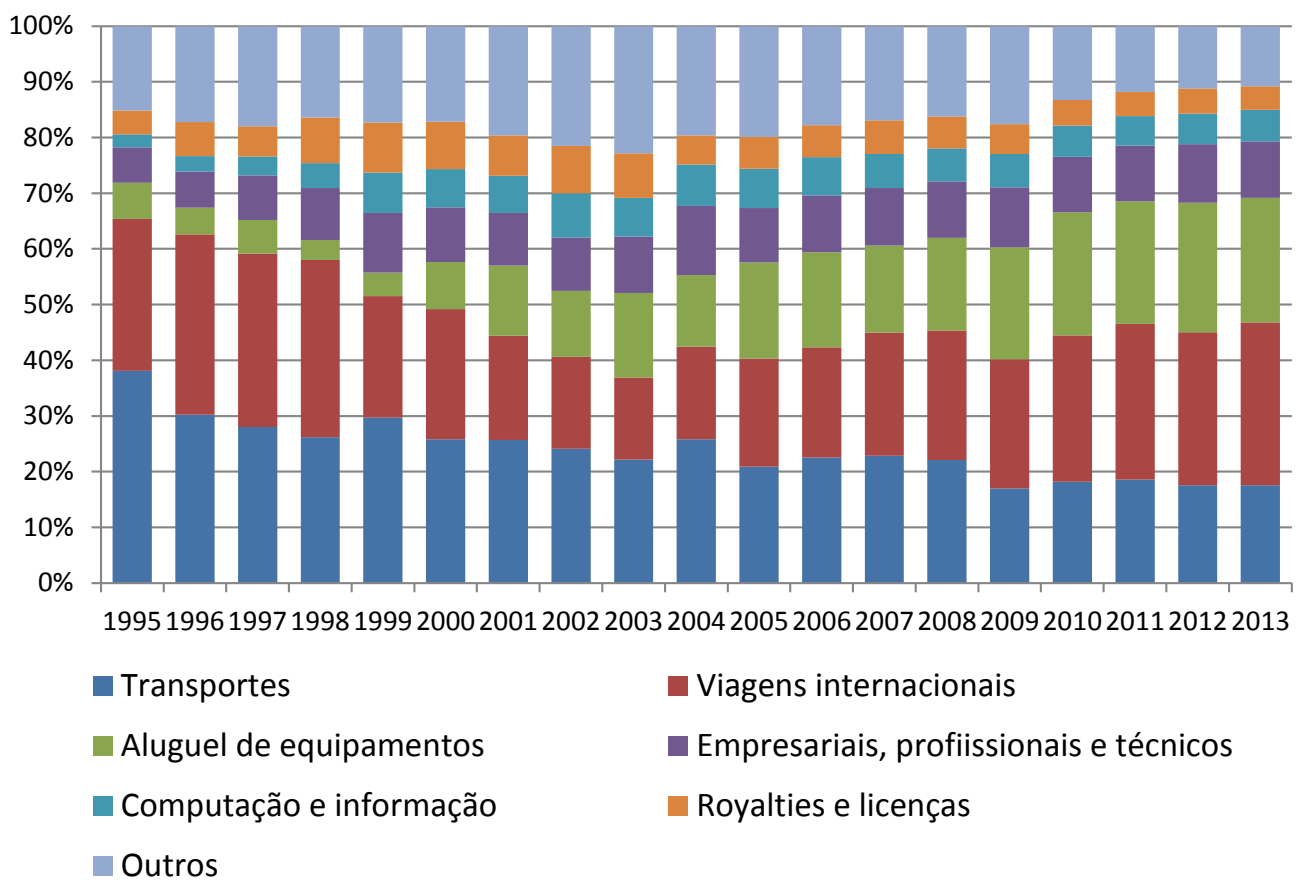

Fonte: Elaboração com base nos dados do BCB.

Dada a ênfase do texto na desagregação das importações por categoria de uso, cumpre notar que as importações de BCD e BCND consistem essencialmente em bens de consumo finais. No primeiro caso sobressaem os automóveis e em menor proporção aparelhos eletrônicos e eletrodomésticos, e no segundo principalmente

(3) $\mathrm{O}$ ano de 1984 marca a descoberta do primeiro campo gigante em águas profundas de Albacora.

(4) O aumento nas despesas com aluguel de equipamentos pode ser explicado pelos pagamentos realizados pela Petrobras pelo uso de equipamentos de exploração. Apesar de produzidas nacionalmente, diversas plataformas de sondagem e exploração de petróleo são "exportados" pela estatal para suas subsidiárias no exterior por questões tributárias e depois "alugadas" para uso em território nacional. 
medicamentos, produtos farmacêuticos, vestuário, assim como alguns artigos alimentícios como peixes e frutas. Já os bens intermediários são compostos principalmente por autopeças, componentes eletrônicos e compostos químicos diversos, que abarcam três dos cinco bens intermediários com maiores valores importados. As importações de bens de capital, por seu turno, consistem basicamente em máquinas e equipamentos, caminhões e ônibus e em menor medida materiais elétricos e eletrônicos, enquanto que as importações de combustíveis e lubrificantes abarcam majoritariamente compras de petróleo bruto, produtos de refino e óleo combustível. Já destacamos acima a importância dos transportes, viagens e aluguel de equipamentos nas importações de serviços. Os cinco principais itens de cada categoria estão listados no Quadro 1.

Quadro 1

Principais itens de cada categoria importada

\begin{tabular}{|c|c|}
\hline BCD & BCND \\
\hline Automóveis de passageiros & Produtos farmacêuticos e medicamentos \\
\hline Aparelhos eletrodomésticos & Artigos do vestuário e acessórios \\
\hline Aparelhos eletrônicos de som e vídeo & Peixes, crustáceos e moluscos \\
\hline Móveis e demais mobilias & Preparações alimentícias \\
\hline Outros veículos & Produtos de perfumaria e limpeza \\
\hline $\mathbf{B K}$ & C\&L \\
\hline Máquinas e equipamentos de uso industrial & Óleos brutos de petróleo \\
\hline Máquinas e equipamentos de uso geral & Outros produtos do refino de petróleo \\
\hline Caminhões, ônibus e outros veículos & Óleos combustíveis, inclusive diesel \\
\hline Equipamentos e material elétrico & Gasolina automotiva \\
\hline Demais aparelhos eletro-eletrônicos & Álcool \\
\hline $\begin{array}{l}\mathbf{B I} \\
\end{array}$ & Serv. TRA \\
\hline Partes e peças para veículos & Transportes \\
\hline Componentes eletrônicos & Aluguel de Equipamentos \\
\hline Compostos químicos não-petroquímicos ou carboquímicos & Royalties e Licenças \\
\hline \multicolumn{2}{|l|}{ Resinas, elastomeros e fibras artificiais e sintéticas } \\
\hline \multicolumn{2}{|l|}{ Adubos, fertilizantes e correntivos do solo } \\
\hline \multicolumn{2}{|l|}{ Serv. Outros } \\
\hline \multicolumn{2}{|l|}{ Viagens Internacionais } \\
\hline \multicolumn{2}{|l|}{ Empresatiais, Profissionais e Tecnicos } \\
\hline \multicolumn{2}{|l|}{ Computação e Informação } \\
\hline \multicolumn{2}{|l|}{ Financeiros } \\
\hline Seguros & \\
\hline
\end{tabular}

Fonte: Funcex e BCB.

Registre-se que no ano de 2013 os cinco bens intermediários mais importantes somaram, em valores nominais, cerca de $18 \%$ das importações totais ${ }^{5}$ valor maior do que as importações de bens de capital (11\%) e do que a soma das

(5) Divididos em 5.6\% de parte e peças para veículos, 3.7\% de componentes eletrônicos e $8.5 \%$ para os três tipos de componentes químicos. 
importações de BCD e BCND (10\%). O maior item individual das importações é o gasto com viagens internacionais ( $7.8 \%$ das importações totais) - que, por seu turno, equivale a pouco menos de dois terços da soma das despesas com transportes, royalties e alugueis de equipamentos (12\%). Por fim, $75 \%$ das importações de combustíveis - que correspondem a $13 \%$ das importações totais - se concentram em óleos brutos de petróleo e outros produtos de refino de petróleo.

Destaque-se, ainda, que as duas categorias de bens de consumo são compostas por bens finais para os quais existem produtos nacionais equivalentes ${ }^{6}$. Espera-se, assim, que a elevação dos preços desses bens importados em função de uma desvalorização cambial tenha reflexos expressivos em suas quantidades demandadas. Um caso diametralmente oposto é verificado para combustíveis, transportes, aluguel de equipamentos e royalties. A demanda interna por petróleo e derivados deve estar vinculada ao nível de atividade da economia e principalmente à capacidade de abastecer plenamente o mercado interno com a exploração e refino nacionais. Deste modo, não há motivo para que um encarecimento relativo das importações leve, pelo menos no curto e médio prazos, a reduções significativas no consumo interno de combustíveis e outros derivados de petróleo. Os itens inclusos na categoria Serv. TRA são um caso ainda mais evidente de produtos preçoinelásticos. Devido à ausência de uma marinha mercante nacional, bem como a natureza contábil das despesas com royalties e aluguel de equipamentos não há justificativa para que qualquer destas despesas seja sensível a variações no câmbio ${ }^{7}$.

As importações de bens de capital, por seu turno, estão no cerne do processo de estrangulamento descrito por Tavares (1972) que ensejou a industrialização por substituição de importações. Entretanto, existe hoje uma expressiva produção nacional de bens de capital. Logo, mesmo que ainda importemos diversas máquinas de equipamentos de maior conteúdo tecnológico, espera-se que haja algum grau de substituição nos bens de capital. Basta verificar que diversos dos $B K$ listados no Quadro 1 acima são fabricados nacionalmente, como caminhões, máquinas agrícolas e materiais elétricos diversos.

Por fim, cumpre notar - no caso dos bens intermediários - que grande parte destes bens são insumos para processos industriais específicos. Ou seja, a substituição de bens intermediários está, em grande medida, ligada a novos investimentos e/ou alterações significativas nos processos produtivos - sendo natural

(6) Ainda que a substituição entre a produção doméstica e a oferta internacional desses bens esteja longe de ser perfeita. É sabido que parte das importações de automóveis corresponde a veículos de luxo. O mesmo caso se aplica a diversos bens de consumo não duráveis importados como perfumes, roupas e certos tipos de alimentos. De todo modo, esses bens possuem algum substituto mesmo que imperfeito produzido internamente.

(7) Ainda que se espere que os fretes guardem uma correspondência próxima com o nível de atividade interna e mundial. É um fato estilizado que a corrente de comércio internacional, e consequentemente os serviços de transporte, tendem a crescer mais rapidamente do que a renda em períodos de expansão e também reduzir-se de forma análoga. 
supor, portanto, que a demanda por esses bens dependa mais de fatores tecnológicos ${ }^{8}$ do que de variações cambiais no curto prazo de alguns poucos trimestres.

Ao considerar os principais $B I s$ importados da pauta brasileira atual temos ainda mais justificativas para pessimismo quanto à elasticidade-preço das importações. O maior item desta categoria, a saber, partes e peças para veículos, está inteiramente inserido no contexto das cadeias globais de valor - vale dizer, as importações desses bens estão sujeitas às estratégias de empresas multinacionais que controlam o mercado automobilístico brasileiro. Com o aval do governo, é bom que se diga, posto que, apesar da efetiva proteção no mercado automobilístico brasileiro, "as tarifas do setor de autopeças são substancialmente menores do que aquelas do setor de veículos" (De Negri, 2010, p. 202).

Já as importações de componentes eletrônicos e diversos compostos químicos enfrentam uma situação clara de deficiência de oferta. A produção nacional de eletrônicos é "(...) fortemente assentada em montagem de bens (...) para uso final no país" (Sarti; Hiratuka, 2010, p. 201) com escassa produção de intermediários como microchips e semicondutores. A indústria química brasileira não é diferente $\mathrm{e}$ se concentra principalmente em commodities químicas orgânicas como resinas plásticas. Nas palavras de Bastos e Costa (2011, p. 166):

A forte dependência de importações resulta (...) também da insuficiência da oferta doméstica e da limitada diversificação da produção química brasileira, apoiada em um leque reduzido de produtos e subcadeias químicas comparado ao padrão altamente diversificado da indústria mundial (...).

Não surpreende, assim, que o Gráfico 4 indique que a forte elevação do quantum importado de bens intermediários se dá tanto em períodos de queda quanto de aumento dos preços.

Gráfico 4

Importações de BI (índice 2006=100)

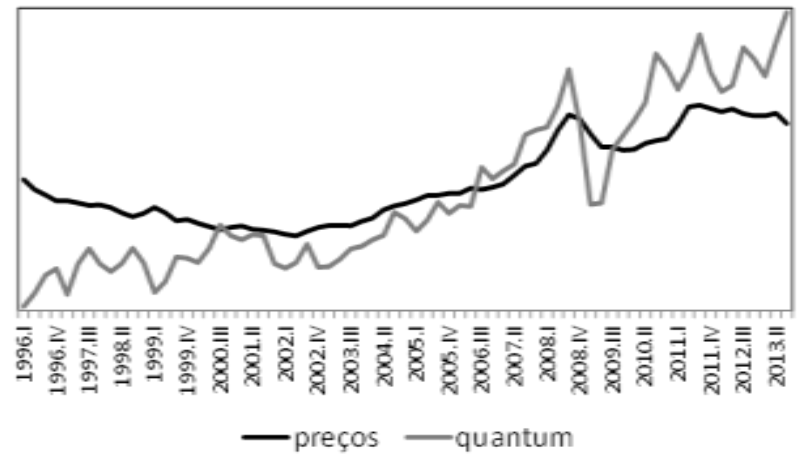

Fonte: Elaboração com base nos dados da Funcex.

(8) Cuja dinâmica, cumpre acrescentar, é, em ampla medida, exógena à economia nacional, tendo em vista o grande peso de corporações multinacionais no setor industrial brasileiro. 


\section{Uma breve resenha seletiva da literatura econométrica sobre a dinâmica das importações brasileiras desagregadas por categorias de uso}

A literatura econométrica sobre a dinâmica das importações brasileiras é bastante rica, constituída por dezenas de textos escritos desde, pelo menos, a década de 1980. Particularmente importantes para os propósitos deste trabalho são os estudos que procuram modelar explicitamente a dinâmica das importações desagregadas "por categoria de uso" a partir de técnicas de cointegração ${ }^{9}$ - e.g. Portugal (1992), Cavalcanti e Castro (1997), Carvalho e Parente (1999), Resende (2001), Cavalcanti e Frischtak (2001) e Sapienza (2007). As especificações utilizadas e os resultados obtidos por estes autores são apresentados na Tabela 1.

\section{Tabela 1}

Estudos com análises de cointegração para o quantum das importações desagregadas por categorias de uso

\begin{tabular}{|c|c|c|c|c|c|c|c|c|c|c|c|c|c|c|c|}
\hline \multirow[t]{2}{*}{ Estudos } & \multirow[t]{2}{*}{ Variáveis explicativas } & \multirow[t]{2}{*}{ Frequência } & \multirow[t]{2}{*}{ Amostra } & \multicolumn{6}{|c|}{ Elasticidade-câmbio } & \multicolumn{6}{|c|}{ Elasticidade-renda } \\
\hline & & & & M & $\mathrm{BCD}$ & $\mathrm{BCND}$ & BI & BK & $\mathrm{C} \& \mathrm{~L}$ & M & $\mathrm{BCD}$ & BCND & BI & BK & C\&L \\
\hline Portugal (1992) & $\begin{array}{l}\text { Câmbio, PIB, utilização da } \\
\text { capacidade industrial }\end{array}$ & Trimestral & 1975 e 1988 & -0.9 & - & - & -0.9 & -0.5 & - & 0.3 & - & - & 1.0 & 1.3 & - \\
\hline $\begin{array}{l}\text { Castro e Cavalcanti } \\
(1997)^{1}\end{array}$ & Câmbio, PIB & Anual & 1956 e 1995 & -3.3 & -1.6 & - & -2.0 & -2.2 & - & 0.5 & 0.8 & - & 1.2 & 1.0 & - \\
\hline Carvalho e Parente (1999) & $\begin{array}{l}\text { Câmbio, PIB, utilização da } \\
\text { capacidade industrial }\end{array}$ & Mensal & $1978-1996$ & - & -2.9 & -1.4 & -2.0 & -1.9 & -0.6 & - & 1.7 & - & 1.3 & 1.3 & - \\
\hline Resende $(2001)^{3}$ & $\begin{array}{l}\text { Câmbio, PIB, utilização da } \\
\text { capacidade industrial e } \\
\text { capacidade de importar }\end{array}$ & Trimestral & $1978-1998$ & -1.4 & -1.5 & -1.0 & -1.1 & -1.5 & - & 3.4 & 2.4 & 1.5 & 3.5 & 3.5 & - \\
\hline $\begin{array}{l}\text { Frischtak e Cavalcanti } \\
\text { (2001) }\end{array}$ & Câmbio e PIB & Trimestral & $1980-2000$ & -0.7 & -1.5 & -1.0 & -1.1 & -1.5 & - & 3.4 & 6.3 & 2.3 & 2.8 & 1.9 & - \\
\hline Sapienza $(2007)^{4}$ & $\begin{array}{l}\text { Câmbio, PIB, capacidade } \\
\text { de importar. }\end{array}$ & Trimestral & $1980-2006$ & 1.3 & -1.8 & -2.5 & 0.7 & 0.8 & - & -1.6 & 4.6 & 2.4 & -0.1 & -2.0 & - \\
\hline
\end{tabular}

(1) Castro e Cavalcanti (1997) estimam a demanda por importações de bens de consumo totais, sem desagregá-la em BCND e BCD.

(2) Carvalho e Parente (1999) não inclui o PIB na demanda por importações de BCND e C\&L.

(3) Resende (2001) não inclui a taxa de câmbio real na demanda por importações de BI e BK.

(4) Sapienza (2007, p. 13) reconhece prontamente que "no caso das importações totais e de bens de capital os sinais [das elasticidades-renda e preço] encontrados foram contrários ao esperado pela teoria econômica." O mesmo é verdadeiro também para os bens intermediários, entretanto.

Estes estudos, de modo geral, indicam elasticidades-preço expressivas, quase sempre maiores do que a unidade. Estimam também elasticidades-renda positivas e aparentemente crescentes entre o início das décadas de 1990 e 2000.

Em relação às categorias descritas na seção 1 percebe-se que as elasticidades-preço dos bens de consumo apresentam valores elevados, como presumido. Os parâmetros dos bens de capital também são elásticos. Também em linha com a descrição anterior a única estimativa que considera os combustíveis encontra um valor reduzido de -0.6.

(9) Tendo em vista as fortes evidências empíricas - encontradas neste estudo e em vários outros textos - de que as séries relevantes têm raízes unitárias. 
Os intermediários se mostram mais sensíveis ao câmbio real do que indica nossa exposição da seção 1. Todavia, como já indicamos, esta categoria sofreu grande aumento do quantum importado na última década. É plausível supor, portanto, que a partir do final do século passado tenha havido uma mudança na estrutura produtiva brasileira - e, por conseguinte, na dinâmica das importações dos BI - que não foi captada nos estudos em questão.

Cumpre mencionar, em particular, as profundas transformações da indústria automobilística nacional desde a abertura comercial e do regime automotivo brasileiro - não apenas por meio da entrada de novas montadoras de capital transnacional, mas também pelas mudanças no relacionamento entre essas montadoras e seus fornecedores de autopeças por meio do "aproveitamento das plataformas globais para criar capacidade de montagem mais genérica e menos presa a modelos específicos, buscando a flexibilidade de suas plantas" (Torres; Cairo, 2012, p. 78).

Em relação à indústria eletroeletrônica, a década de 1990 foi marcada por uma intensa fragmentação da produção ${ }^{10}$ e também aumento da participação dos eletrônicos no comércio mundial. Concomitantemente, as exportações de partes e componentes cresceram mais rápido do que as de produtos finais (Lall; Albadejo; Zhang, 2004, p. 8). Aliados à ausência de uma produção nacional de componentes eletrônicos estes fatos esclarecem não só o aumento do quantum importado de intermediários, mas também constituem uma possível explicação para sua baixa elasticidade-preço.

De um ponto de vista metodológico, é importante dividir a literatura em textos que consideram e não consideram explicitamente a possibilidade e as implicações de múltiplas quebras estruturais, tanto na dinâmica individual das séries quanto na relação entre elas. Há vastas evidências na literatura de quebras estruturais dos dois tipos e a existência destas quebras têm pelo menos três consequências importantes. Primeiramente, os resultados dos testes de raízes unitárias convencionais são afetados (Lee; Strazicich, 2003). Segundo, dummies nos VARs de partida provavelmente terão que ser utilizadas quando da implementação dos testes de Johansen $(1988,1991)$ a fim de garantir erros homocedásticos e não correlacionados. Em terceiro lugar, os resultados dos testes de (não) cointegração clássicos (Engle; Granger, 1987; Johansen, 1988, 1991) não são válidos na presença de quebras estruturais na relação de cointegração (Gregory; Hansen, 1996) e são

(10) Segundo Lall, Albadejo e Zhang (2004, p. 1) a fragmentação da produção no complexo eletroeletrônico foi mais rápida do que no automobilístico. 
enviesados no sentido de uma identificação espúria de relações de cointegração quando há quebras estruturais nas séries (Leybourne; Newbold, 2003; Cook, 2004).

Uma vez que vários dos resultados supracitados só ficaram disponíveis após a virada do século, não surpreende que os estudos listados na Tabela 1 lidem de forma sub-ótima com - ou mesmo desconsiderem - a possibilidade de quebras estruturais nos dados/relações de cointegração relevantes. Adicionalmente, as amostras utilizadas nos referidos estudos são, por motivos óbvios, bastante diferentes das utilizadas neste trabalho. Registre-se, por fim, que nenhum dos estudos mencionados leva em conta as importações de serviços que constituem cerca de $20 \%$ das importações brasileiras totais.

\section{Metodologia}

\section{Os procedimentos econométricos adotados neste texto}

Os procedimentos econométricos adotados neste trabalho têm como objetivo explícito tratar - ou pelo menos mitigar - os problemas decorrentes da presença de múltiplas quebras estruturais e ainda atentar para o possível viés de endogeneidade nas equações estimadas. Não parece injusta a afirmação de que tais problemas afetam praticamente todos os textos citados na Tabela 1.

O primeiro passo da estratégia econométrica adotada consiste na análise dos resultados dos testes de raiz unitária de LS (Lee; Strazicich, 2003), ZA (Zivot; Andrews, 1993) e ADF-t (Quadro 2). Dois casos são dignos de nota. Em primeiro lugar, as relações relevantes podem envolver apenas séries estacionárias ou, alternativamente, combinações de séries estacionárias e não estacionárias. Neste caso, estimam-se modelos VAR clássicos, uma vez que Sims, Stock e Watson (1990) mostram que este procedimento será consistente se "o[s] modelo[s] puder[em] ser reescrito[s] de maneira que os coeficientes sob inspeção passem a multiplicar variáveis estacionárias" (Bueno, 2008, p. 172).

Segundo, as relações relevantes podem envolver apenas séries não estacionárias, caso que contempla a maior parte das especificações deste texto. Neste caso, analisam-se inicialmente os resultados dos testes de Engle e Granger (1987) e Gregory e Hansen (1996) - respectivamente EG e GH daqui por diante ${ }^{11}$. Três possibilidades devem ser levadas em consideração. Primeiro, é possível que a existência de quebras estruturais nas séries seja rejeitada pelos testes de Lee e Strazicich (LS). Neste caso, os resultados do teste EG devem ser examinados à luz

(11) Considera-se aqui que a existência de múltiplas quebras estruturais nas séries e nas relações de cointegração torna desaconselhável a aplicação dos testes de Johansen (1988, 1991). 
da aplicação do teste de $\mathrm{GH}$ a fim de controlar pela existência de quebras estruturais nas relações de cointegração. Em segundo lugar, é possível que a existência de quebras estruturais nas séries não seja rejeitada pelos testes LS e não se encontre evidências de cointegração nos testes mencionados. Neste caso, é bastante provável que não exista cointegração entre as variáveis, em vista os resultados de Leybourne e Newbold (2003) e Cook (2004). Por fim, é possível que a existência de quebras estruturais nas séries não seja rejeitada pelos testes LS e que se encontre evidências de cointegração nos testes mencionados. Neste caso, os resultados de Leybourne e Newbold (2003) e Cook (2004) sugerem a possibilidade de que as evidências de cointegração sejam espúrias.

Para se controlar por esta última possibilidade - e pela provável existência de não linearidades mais complexas do que simples quebras estruturais nos dados estejam a enviesar os resultados dos testes EG e GH - estimam-se também modelos Markovianos de alternância de regimes (Hamilton, 1989 e 1994). Tais modelos aninham a existência de uma ou mais quebras estruturais na relação entre as variáveis como casos particulares - e são utilizados aqui como testes de robustez dos resultados qualitativos obtidos com a análise de cointegração.

A existência de quebras estruturais nas relações de cointegração prejudica ainda a aplicação dos testes de exogeneidade convencionais - que partem da especificação de um modelo vetorial de correção de erros com erros bem comportados e vetor(es) de cointegração constante(s) obtidos por meio da análise de Johansen convencional. Daí a opção por examinar a possibilidade da existência do viés de endogeneidade nas especificações baseadas na existência de um único vetor de cointegração por meio do exame das funções impulso-resposta de VARs congruentes construídas a partir de várias hipóteses diferentes de identificação.

\section{Descrição das variáveis}

Além dos dados desagregados já descritos utilizamos a séries de importações agregadas das contas nacionais trimestrais (CNTVIBGE). Os dois gráficos a seguir ilustram a compatibilidade entre a soma das categorias desagregadas ${ }^{12}$ e o total importado $(M)$, em termos nominais e em taxas de crescimento real. As séries utilizadas se estendem do primeiro semestre de 1996 até o segundo de 2013, totalizando 70 observações.

(12) Todas free on board (FOB). Os valores nominais em milhões de dólares foram convertidos pelo câmbio nominal médio de cada período. 


\section{Gráfico 5}

Importações nominais das CNT reconstruídas a partir de dados da Funcex e do Bacen* (esq) e

Taxas de Crescimento do Volume Total Importado** (dir)
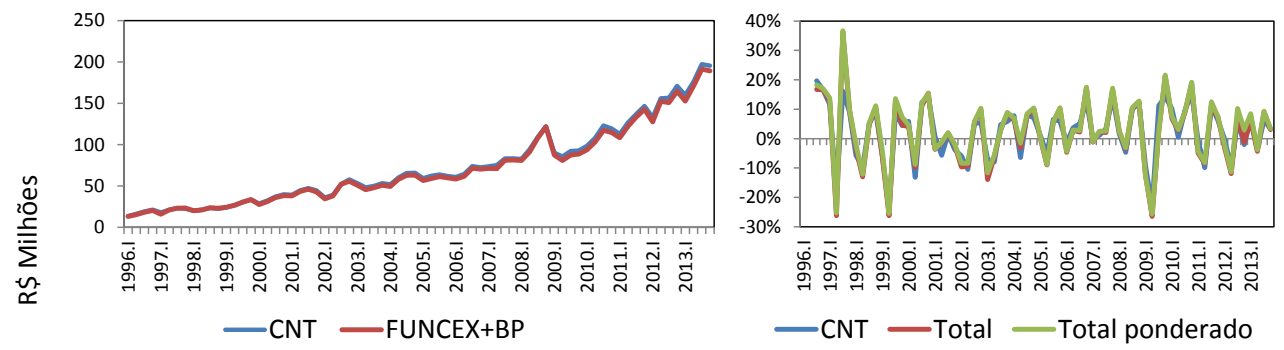

* As pequenas diferenças entre as séries construídas com dados da funcex e do IBGE podem ser atribuídas ao fato de que os dados da Funcex não incluem as importações de serviços.

** As taxas de crescimento anualizadas da série trimestral de importações a preços de 1995 das CNT são compatíveis com as taxas de crescimento reais calculadas a partir das importações nas tabelas de recursos e usos (TRU) após o ajuste FOB/SIF. As taxas de crescimento da TRU são obtidas comparando $o$ valor das importações a preços correntes de um ano $t$ com $o$ valor das importações em $t+1$ a preços do ano anterior.

Fonte: Elaboração com base nos dados do IBGE e Funcex.

Naturalmente, as variáveis de interesse utilizadas nas regressões são expressas em termos reais ${ }^{13}$. Ademais, em todas as especificações estimadas utilizamos a mesma variável como proxy da demanda por importações $(Y)$ : a série do produto interno bruto, em termo reais, com ajuste sazonal, também das contas nacionais trimestrais ${ }^{14}$.

Por fim, foram construídas variáveis de câmbio real para cada uma das desagregações analisadas: $e_{i}=\frac{E \cdot P_{i}^{*}}{P} \cdot(1+t)$

Onde $E$ é a taxa de câmbio nominal, $P_{i}^{*}$ o índice de preços das importações das categorias de uso, $P$ o índice de preços ao atacado do Brasil e $t$ a alíquota efetiva de importação ${ }^{15}$. Para as duas variáveis referentes a serviços foi utilizada a taxa de câmbio real agregada, onde $P_{i}^{*}$ é o índice de preços ao atacado dos Estados Unidos.

(13) Portanto, além dos índices de quantum das categorias de uso dos bens disponibilizados pela Funcex utilizou-se para as importações agregadas o índice encadeado e dessazonalizado das importações a preços constantes, disponível nas CNT. Já as séries nominais de despesas com serviços em dólares foram deflacionados pelo índice de preços ao consumidor dos EUA. Todas as variáveis estão em logaritmos e foram dessazonalizadas pelo método x-12 multiplicativo utilizando o Gretl. Exceto as importações agregadas que já estão dessazonalizadas nas CNT

(14) Poder-se ia pensar, por exemplo, em usar o consumo das famílias como variável de demanda para as importações de BCD e BCND. Ou a formação bruta de capital fixo como variável de demanda para as importações de BK. A análise destas especificações alternativas faz parte de um segundo texto ora em andamento.

(15) Cuja proxy utilizada foi a divisão do valor nominal da arrecadação de impostos de importação pelo total nominal das importações nominais. 
A ideia é captar mudanças de preço relativo não relacionadas as taxas de câmbio que também podem afetar as importações - o que parece especialmente importante no caso dos combustíveis e lubrificantes (Gráfico 7).

Todas as variáveis são devidamente descritas no Quadro 2 abaixo.

Quadro 2

Descrição das Variáveis

\begin{tabular}{|c|c|c|c|c|}
\hline Variável & Sigla & Descrição & Fonte & Tabela/Código \\
\hline Importações agregadas & M & $\begin{array}{l}\text { logarítmo natural da série encadeada do índice de } \\
\text { volume trimestral com ajuste sazonal }(1995=100)\end{array}$ & $\begin{array}{l}\text { IBGE/SCN/Contas } \\
\text { Trimestrais } \\
\text { ref.2000 }\end{array}$ & Tabela 7 \\
\hline Importações de bens de consumo duráveis & $B C D$ & $\begin{array}{l}\text { logarítmo natural da média trimestral do índice } \\
\text { mensal de quantum (2006=100) }\end{array}$ & FUNCEX & FUNCEX12_MDQBCD12 \\
\hline Importações de bens de consumo não duráveis & $B C N D$ & $"$ & " & FUNCEX12_MDQBCND12 \\
\hline Importações de bens intermediários & $B I$ & $"$ & $"$ & FUNCEX12_MDQB|12 \\
\hline Importações de bens de capital & $B K$ & $"$ & " & FUNCEX12_MDQBK12 \\
\hline Importações de combustíveis e lubrificantes & $C \& L$ & $"$ & $"$ & FUNCEX12_MDQCOMB12 \\
\hline $\begin{array}{l}\text { Importação de serviços de transporte, } \\
\text { pagamento de royalties e aluguéis de } \\
\text { equipamentos }\end{array}$ & Serv.TRA & $\begin{array}{l}\text { logarítmo natural do índice construido a partir da série } \\
\text { trimestral de despesas com serviços de transporte, } \\
\text { pagamentos de royalties e aluguéis de equipamentos } \\
\text { do Balanço de Pagamentos deflacionada pelo índice de } \\
\text { preços ao consumidor (CPI) americano }\end{array}$ & $\mathrm{BCB}, \mathrm{BLS} / \mathrm{USDOL}$ & \\
\hline Importações dos demais serviços & Serv.Outros & $\begin{array}{l}\text { logarítmo natural do índice construido a partir da série } \\
\text { trimestral de despesas com os demais serviços do } \\
\text { Balanço de Pagamentos deflacionada pelo índice de } \\
\text { preços ao consumidor (CPI) americano }\end{array}$ & $\mathrm{BCB}, \mathrm{BLS} / \mathrm{USDOL}$ & $\begin{array}{l}\text { BCB/Séries Temporáis/Tabelas } \\
\text { Especiais/Setor Externo/Balanço } \\
\text { de Pagamentos }\end{array}$ \\
\hline Demanda Agregada & Y & $\begin{array}{l}\text { logarítmo natural da série encadeada do índice de } \\
\text { volume trimestral com ajuste sazonal (1995=100) }\end{array}$ & $\begin{array}{l}\text { IBGE/SCN/Contas } \\
\text { Trimestrais } \\
\text { ref. } 2000\end{array}$ & Tabela 7 \\
\hline Taxa de cambio real - agregada & $e$ & $\begin{array}{l}\text { logarítimo natural da média trimestral entre as taxas } \\
\text { de cambio livres médias de compra e venda, } \\
\text { multiplicadas pelo índice de preços no atacado (IPA) } \\
\text { dos EUA e dívidido pelo IPA nacional; ajustada pela } \\
\text { alíquota efetiva sobre importações calculada pela } \\
\text { divisão da arrecadação de impostos de importação } \\
\text { pelo valor nominal das importações totais. }\end{array}$ & $\begin{array}{c}\text { SGS/BCB, } \\
\text { FGV/Conjuntura } \\
\text { Econômica - IGP, } \\
\text { FMI/IFS, } \\
\text { IBGE/SCN/CNT }\end{array}$ & $\begin{array}{l}\text { SGS/BCB séries 3697, } 3698 \text { e } \\
\text { 7635. FGV: IGP12_IPADI12. FMI: } \\
\text { IFS4_IPAEUA4. E IBGE Tabela } 9 .\end{array}$ \\
\hline $\begin{array}{l}\text { Taxa de cambio real - bens de consumo } \\
\text { duráveis }\end{array}$ & e.bcd & $\begin{array}{l}\text { calculo igual a } e \text {, substituindo IPA dos EUA pelo índice } \\
\text { de preços dos bens de consumo duráveis (média } \\
2006=100 \text { ) }\end{array}$ & FUNCEX & FUNCEX12_MDPBCD12 \\
\hline $\begin{array}{l}\text { Taxa de cambio real - bens de consumo não } \\
\text { duráveis }\end{array}$ & e.bend & $\begin{array}{l}\text { calculo igual a } e \text {, substituindo IPA dos EUA pelo índice } \\
\text { de preços dos bens de consumo duráveis (média } \\
2006=100 \text { ) }\end{array}$ & FUNCEX & FUNCEX12_MDPBCND12 \\
\hline Taxa de cambio real - bens intermediários & e.bi & $\begin{array}{l}\text { calculo igual a } e \text {, substituindo IPA dos EUA pelo índice } \\
\text { de preços dos bens de consumo duráveis (média } \\
2006=100 \text { ) }\end{array}$ & FUNCEX & FUNCEX12_MDPBI12 \\
\hline Taxa de cambio real - bens de capital & $e . b k$ & $\begin{array}{l}\text { calculo igual a } e \text {, substituindo IPA dos EUA pelo índice } \\
\text { de preços dos bens de consumo duráveis (média } \\
2006=100 \text { ) }\end{array}$ & FUNCEX & FUNCEX12_MDPBK12 \\
\hline $\begin{array}{l}\text { Taxa de cambio real - combustíveis e } \\
\text { lubrificantes }\end{array}$ & e.c\&l & $\begin{array}{l}\text { calculo igual a e, substituindo IPA dos EUA pelo índice } \\
\text { de preços dos bens de consumo duráveis (média } \\
\qquad 2006=100 \text { ) }\end{array}$ & FUNCEX & FUNCEX12_MDPCOMB12 \\
\hline
\end{tabular}


Gráfico 6

Taxas de Câmbio Reais (em logaritmos neperianos)

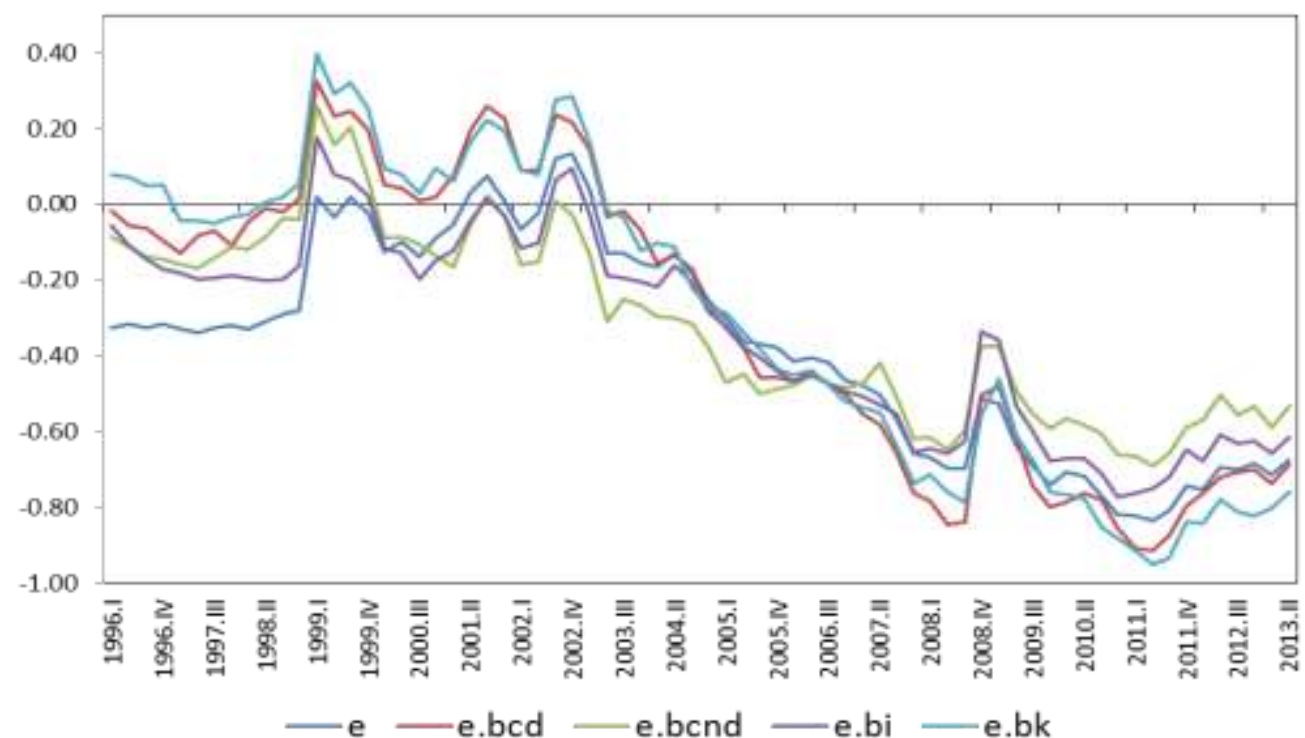

Nota: e: taxa de câmbio real agregada; e.bcd: taxa de câmbio real de bens de consumo duráveis; e.bcnd: taxa de câmbio real de bens de consumo não duráveis, e.bi: taxa de câmbio real de bens intermediários, e.bk: taxa de câmbio real de bens de capital.

Fonte: Elaboração com base em dados da Funcex, FGV, BCB, IBGE e BLS/USDOL

Gráfico 7

Taxa de Câmbio Real - Combustíveis e Lubrificantes (em logaritmos neperianos)

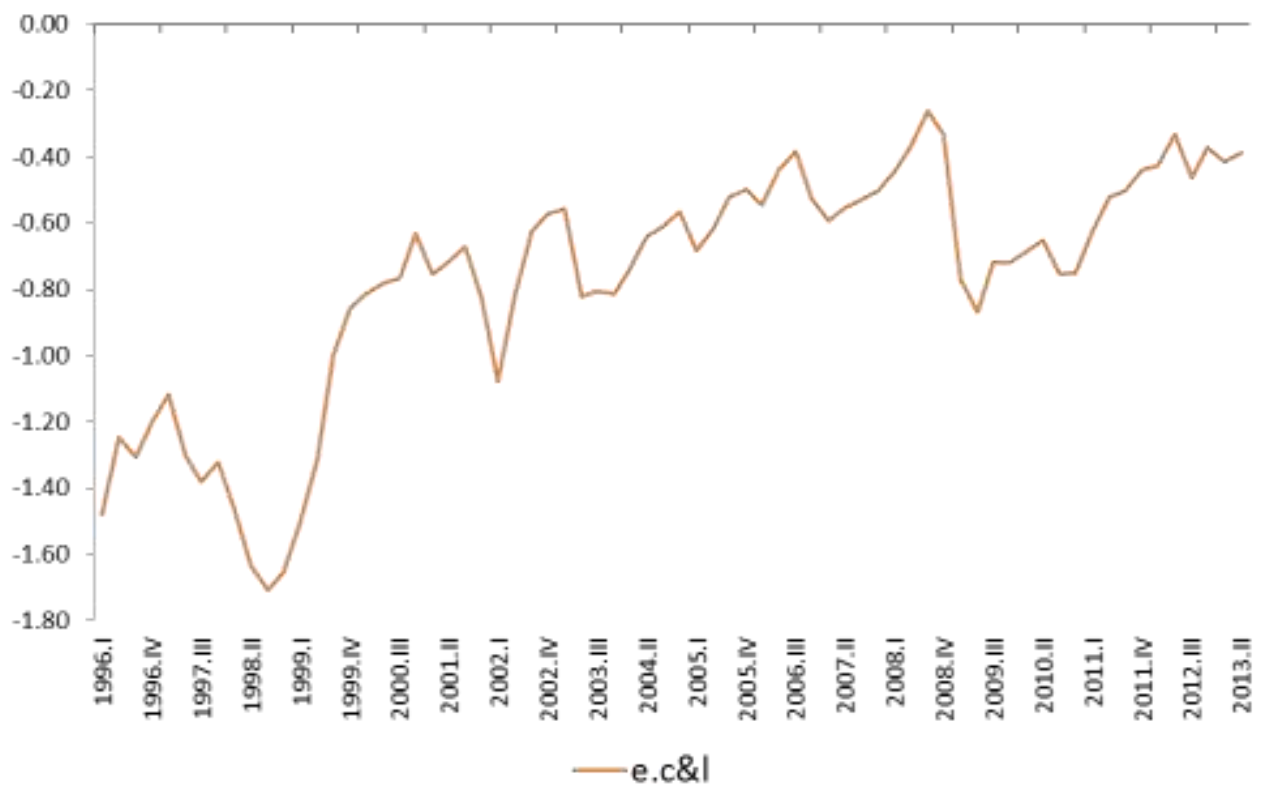

Fonte: Elaboração com base em dados da Funcex, FGV, BCB, IBGE. 
A análise gráfica das séries das importações brasileiras sugere a existência de - por vezes múltiplas - quebras estruturais (e.g. Gráfico 7). Daí a opção por examinar a possibilidade de existência de raízes unitárias nas 8 variáveis de importações e no PIB (que apresentam tendência) por meio dos supracitados testes de LS e $\mathrm{ZA}^{16}$. No caso das variáveis que não apresentam tendência, as taxas de câmbio, foi utilizado o tradicional teste ADF.

Tabela 2

Testes de Raiz Unitária ${ }^{(1)}$

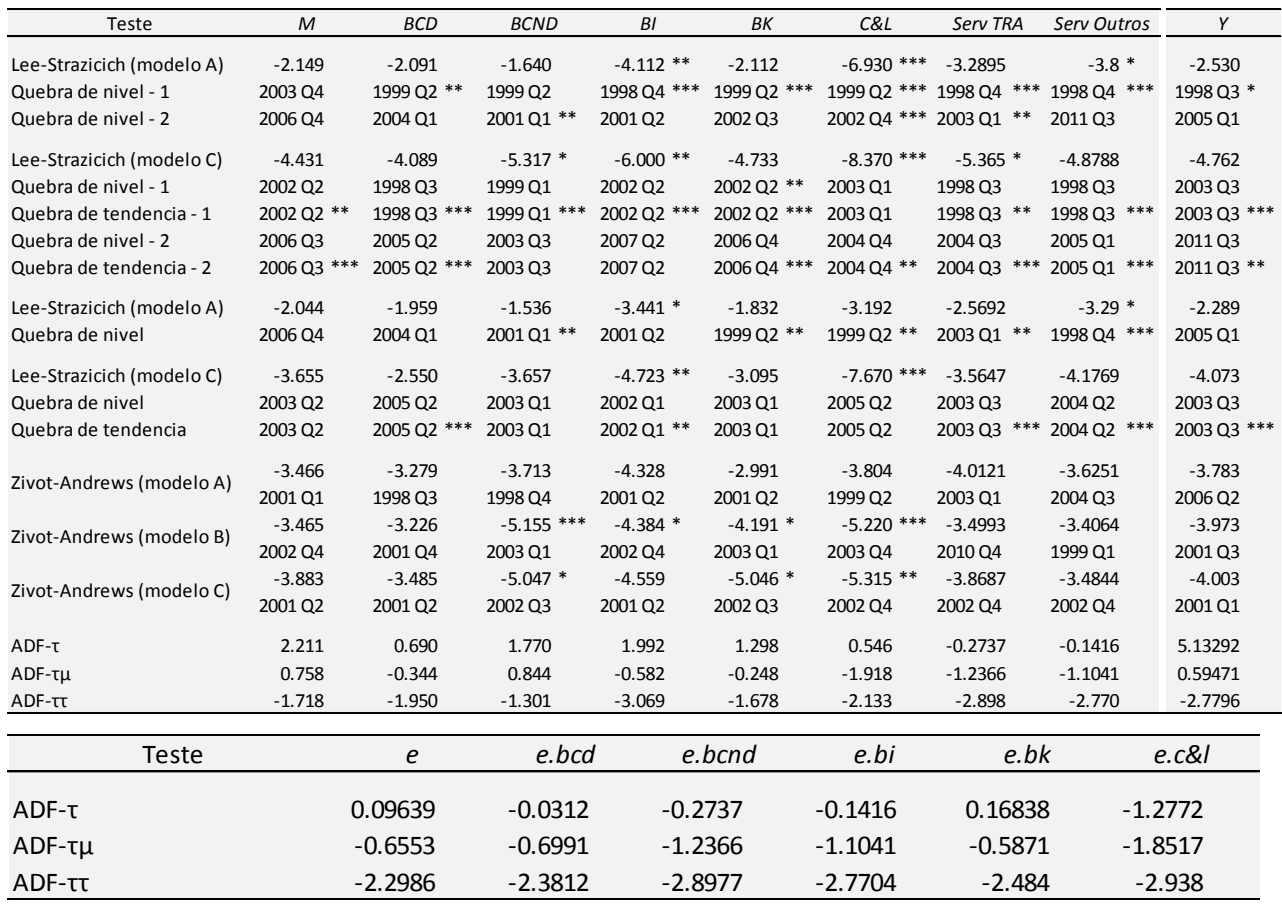

*** rejeita $\mathrm{H0}$ a $1 \%$; ** rejeita $\mathrm{H0}$ a $5 \%$; * rejeita $\mathrm{H0}$ a $10 \%$

(1) Os modelos A, B e C indicam especificações com quebras estruturais apenas no nível, apenas na tendência e em ambos, respectivamente.

Os resultados sugerem a existência de duas quebras estruturais em $M, B C D, B K, \operatorname{Serv}$ Outros, ServTRA e $Y$, todas $\mathrm{I}(1)^{17}$. O mesmo teste sugere a existência de apenas um quebra estrutural em $B C N D$, também I(1). Os resultados

(16) O teste ZA (Zivot; Andrews, 1992) testa a hipótese nula de um passeio aleatório com tendência e sem quebras contra a alternativa de um processo estacionário em torno de uma tendência determinística com uma quebra estrutural. Já o teste LS (Lee; Strazicich, 2003) testa a hipótese nula de um passeio aleatório com tendência e até duas quebras estruturais contra a hipótese alternativa de um processo estacionário em torno de uma tendência determinística com até duas quebras estruturais. O teste LS tem ainda a vantagem de nos permitir testar a significância das referidas quebras estruturais.

(17) Na série Serv. TRA deve-se decidir entre os dois testes de LS com duas quebras. O modelo A indica estacionariedade enquanto o modelo $\mathrm{C}$ indica uma série integrada. A decisão de tratar esta série como I(1) parece encontrar respaldo nas relações de cointegração reportadas mais adiante neste texto. 
indicam fortemente, ainda, que as séries de $C \& L$ e $B I$ são $\mathrm{I}(0)^{18}$. Por fim, os testes indicam que todas as séries de câmbio possuem raízes unitárias na amostra analisada.

\section{Resultados}

Nesta seção apresentamos os resultados dos testes de cointegração e dos modelos markovianos de alternância de regimes $(M S)$, tentando interpretá-los à luz das características estruturais da economia e da pauta de importações brasileira expostas ao decorrer deste trabalho. Para todos os casos foi estimada uma função de demanda por importações contendo as taxas de câmbio real e a demanda interna como variáveis explicativas e as diversas desagregações das importações como variáveis dependentes, conforme a equação (1) abaixo na qual o subscrito $i$ representa cada uma dos 8 índices de quantum dos importado, $M$ representa as importações e $e$ as taxas de câmbio real ${ }^{19}$.

$$
\text { (1) } M_{i, t}=\alpha+\beta_{1} \cdot e_{i, t}+\beta_{2} \cdot Y_{t}+\varepsilon_{t}
$$

\section{Gráfico 8}

Funções de demanda por importação

M

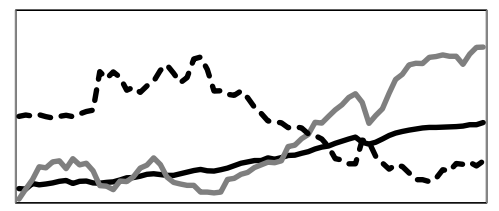

$\longrightarrow \mathrm{Y} \underset{\mathrm{BCND}}{\mathrm{M}}---\mathrm{e}$

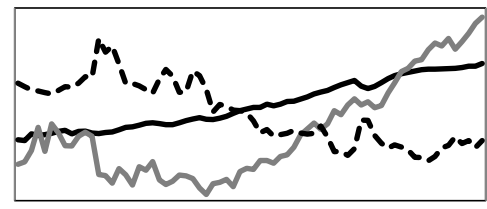

$-\mathrm{Y} \longrightarrow \mathrm{BCND}---\mathrm{e} . \mathrm{bcnd}$ BK

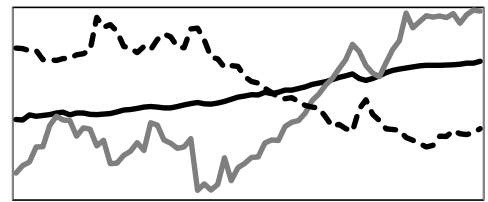

$\longrightarrow \mathrm{Y} \longrightarrow \mathrm{BK}---\mathrm{e} . \mathrm{bk}$
$B C D$

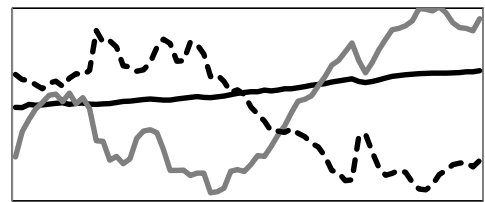

$\longrightarrow \mathrm{Y} \longrightarrow \mathrm{BCD}-\boldsymbol{B}-\mathrm{e} \cdot \mathrm{bcd}$

$\mathrm{BI}$

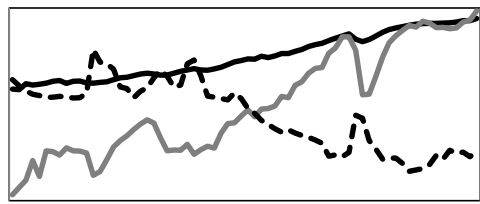

$-\mathrm{Y} \longrightarrow \mathrm{BI}---\mathrm{e} \cdot \mathrm{bi}$

C\&L

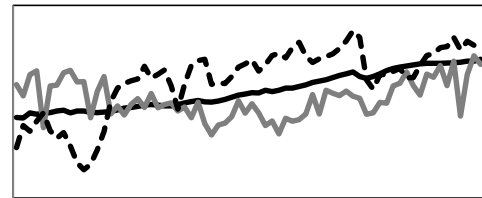

$\longrightarrow \mathrm{Y} \longrightarrow \mathrm{C} \& \mathrm{~L}---\mathrm{e} . \mathrm{C} \& \mathrm{I}$

(18) No primeiro caso por conta do teste LS com duas quebras (modelo A) e no segundo pelo teste de LS com uma quebra (modelo $\mathrm{C}$ ).

(19) Lembrando que a taxa de câmbio real usual $e$ é aplicada tanto as importações agregadas $(M)$ quanto as de serviços (Serv.TRA) e (Serv.Outros). Para as demais categorias temos: e.bcd,e.bcnd, e. bi, e.bk e e.c\&l. 
Serv. TRA

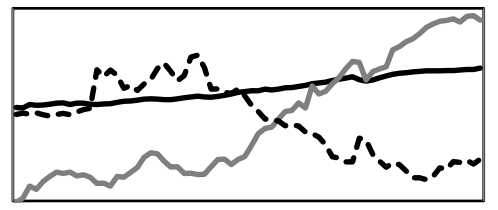

Y m.serv.TRA
Serv. Outros

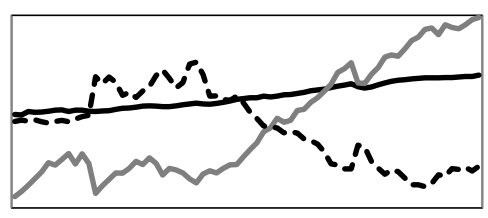

$\mathrm{Y}-\mathrm{m}$. serv.outros - - - e

Nota: M: importações agregadas, BCN: Bens de consumo duráveis, BCND: Bens de consumo não duráveis, BI: Bens intermediários, BK: Bens de capital, C\&L: Combustíveis e lubrificantes, Serv TRA: Serviços de transporte, pagamentos de royalties e aluguéis de equipamentos, Serv Outros: Demais serviços.

Fonte: Elaboração com base em dados da Funcex, FGV, BCB, IBGE e BLS/USDOL.

São reportados na Tabela 3 as estatísticas de teste, o período das quebras estruturais e as elasticidades estimadas nos vetores de cointegração encontrados. Como esperado, feita uma única exceção nos $B C D$, as relações de cointegração foram estimadas pelos testes de $\mathrm{GH}$, portanto, identificando a presença de quebras estruturais nas relações entre as variáveis.

Os testes GH-C, GH-C/T, GH-C/S e GH-C/T/S correspondem a quebras na constante, constante e tendência, constante e nos parâmetros e constante, tendência e parâmetros, respectivamente.

Tabela 3

Testes de Cointegração e Elasticidades

\begin{tabular}{|c|c|c|c|c|c|c|c|}
\hline \multirow[t]{2}{*}{ Classe } & \multirow[t]{2}{*}{ Teste } & \multirow{2}{*}{$\begin{array}{c}\text { Estatística } \\
\text { do Teste }\end{array}$} & \multirow{2}{*}{$\begin{array}{c}\text { Quebra } \\
\text { Estrutura }\end{array}$} & \multicolumn{2}{|c|}{ Elasticidade-Câmbio } & \multicolumn{2}{|c|}{ Elasticidade-Renda } \\
\hline & & & & Antes & Depois & Antes & Depois \\
\hline M & $\mathrm{GH}-\mathrm{C} / \mathrm{S}$ & $-6.26^{* * *}$ & 2002 T1 & -0.51 & 0.11 & 3.17 & 3.29 \\
\hline$M$ & $\mathrm{GH}-\mathrm{C} / \mathrm{S} / \mathrm{T}$ & $-6.57^{* * *}$ & 2002 T2 & -0.37 & 0.15 & 2.22 & 3.89 \\
\hline $\mathrm{BCD}$ & $E G-C$ & $-3.60 *$ & - & -2.00 & - & -0.17 & - \\
\hline $\mathrm{BCD}$ & $\mathrm{GH}-\mathrm{C}$ & $-5.10^{* *}$ & 2003 T3 & -1.99 & - & 1.60 & - \\
\hline BCND & $\mathrm{GH}-\mathrm{C}$ & $-5.45^{* * *}$ & 1998 T3 & 0.62 & - & 3.11 & - \\
\hline BCND & $\mathrm{GH}-\mathrm{T}$ & $-5.45^{* *}$ & 1998 T3 & 0.59 & - & 3.11 & - \\
\hline BK & $\mathrm{GH}-\mathrm{C}$ & $-6.76^{* * *}$ & 2002 T4 & -0.85 & - & 2.01 & - \\
\hline BK & $\mathrm{GH}-\mathrm{T}$ & $-6.84^{* * *}$ & 2002 T4 & -0.69 & - & 3.72 & - \\
\hline BK & $\mathrm{GH}-\mathrm{C} / \mathrm{S}$ & $-7.76^{* * *}$ & 2002 T4 & -0.73 & -0.38 & -0.47 & 3.40 \\
\hline BK & $\mathrm{GH}-\mathrm{C} / \mathrm{S} / \mathrm{T}$ & $-7.72^{* * *}$ & 2002 T4 & -0.79 & -0.38 & -1.31 & 3.30 \\
\hline Serv.TRA & $\mathrm{GH}-\mathrm{C}$ & $-5.62^{* * *}$ & 2002 T3 & -0.36 & - & 4.77 & - \\
\hline Serv.TRA & $\mathrm{GH}-\mathrm{T}$ & $-5.60^{* *}$ & 2002 T4 & -0.77 & - & 2.03 & - \\
\hline Serv.TRA & $\mathrm{GH}-\mathrm{C} / \mathrm{S}$ & $-5.81^{* *}$ & 2002 T3 & -0.25 & -0.20 & 4.00 & 5.12 \\
\hline Serv.outrc & $c \mathrm{GH}-\mathrm{C} / \mathrm{S}$ & $-5.49 *$ & $2002 \mathrm{~T} 1$ & -0.84 & -0.36 & 4.83 & 4.79 \\
\hline Serv.outrc & $\mathrm{C} \mathrm{GH}-\mathrm{C} / \mathrm{S} / \mathrm{T}$ & $-5.92^{* *}$ & 2002 T4 & -1.22 & -0.47 & 2.32 & 2.72 \\
\hline
\end{tabular}

*** rejeita $\mathrm{H} 0$ a $1 \%$; ** rejeita $\mathrm{H} 0$ a $5 \%$; * rejeita $\mathrm{H} 0$ a $10 \%$.

Os resultados estão em grande parte de acordo com a análise da seção 1 . Primeiro, é importante notar a grande concentração das quebras estruturais no final 
de 2002. Como vemos nos Gráficos 7, este ponto está próximo do final de um longo período de estagnação nos índices de volume das importações e da renda, seguido de uma tendência crescente nos anos em que o Brasil experimentou um forte aumento do nível de atividade econômica, dos investimentos (dos Santos, 2013) e do nível de emprego que durou até $2011^{20}$. Não foram realizados testes para C\&L, pois a série é estacionária, enquanto para os BI não foi identificada nenhuma relação de cointegração.

As elasticidades-preço do total importado já eram baixas -0.51 e -0.37 , mesmo antes de 2002 enquanto a renda parecia ter um efeito muito maior para a dinâmica trimestral das importações com elasticidades de 3.17 e 2.22. Como esperado os $B C D$ apresentaram elasticidade-preço e renda altas. Por outro lado, os resultados para os $B C N D$ sugerem uma relação positiva com o câmbio provavelmente associada ao peso dos bens de luxo inseridos nesta rubrica, o que faz com que o consumo destes seja pouco sensível a variações de preço. De todo modo, vale lembrar que ambos constituem uma parcela reduzida do total e, portanto, têm pouca influência nas elasticidades das importações agregadas.

Os $B K$ se mostraram mais elásticos ao câmbio do que o agregado, assim como os outros serviços. Não obstante, ambos também são fortemente influenciados pela demanda doméstica. E, como seria de se esperar, os serviços de transporte, aluguel e royalties apresentaram baixa sensibilidade cambial e alta elasticidaderenda.

Cabe notar que os modelos com quebras estruturais apresentam uma característica comum, qual seja: a queda da elasticidade-preço e aumento da elasticidade-renda após 2002/2003. Este fato é verificado para M, BK e Serv. Outros. Soa razoável, portanto, supor que o câmbio exerça maior efeito nas importações em períodos de estagnação e a demanda durante o crescimento. Mesmo assim, em quase todos os testes reportados a elasticidade-renda supera a elasticidade-preço tanto antes quanto depois das quebras.

Dito isso, cumpre notar que a análise de cointegração apresentada não considera as importações de intermediários e combustíveis que juntas representam cerca de $43 \%$ do total. Daí a necessidade de reportamos, a seguir, os modelos de $\mathrm{MS}^{21}$. Foram estimadas, para cada uma das 8 categorias, especificações que

(20) Entre o final de 2002 e início de 2003 também foram estimadas diversas das quebras identificadas nos testes de LS e ZA, ver Tabela 3.

(21) Os modelos econométricos com alternância de regime remontam à Hamilton (1989). E partem da ideia de permitir que o modelo dependa do estado da economia. Por exemplo, é possível estimar uma equação na qual as mesmas variáveis tenham impactos diferentes sobre o nível de atividade da economia em regimes de recessão e expansão.A especificação de cada um dos regimes é linear, mas a probabilidade de transição entre eles se dá por meio de uma cadeia de Markov, resultando em um modelo não linear estimada por métodos numéricos de máxima verossimilhança. As equações dinâmicas com alternância de regimes nesta seção foram estimadas no pacote PcGive 13, para OxMetrics. O Método de estimação utilizado é o de Programação Quadrática Sequencial Factível (SQPF) padrão do Software. A mudança de regimes é estimada por uma variável aleatória discreta não observada descrita por uma cadeia de Markov para a qual são computadas as probabilidades de transição. Segundo Hamilton (1994, p. 678) "The simplest time series model for a discrete-valued random variable is a Markov Chain". 
permitem alternância do intercepto (MSI), dos coeficientes das variáveis (MSIM), do coeficiente da variância (MSH), e suas combinações MSIH, MSIM e MSIHM ${ }^{22}$, com dois e três regimes.

A Tabela 4 apresenta os valores estimados da elasticidade-preço e renda do melhor modelo estimado para cada categoria das importações ${ }^{23}$. Os valores nulos indicam os modelos nos quais os coeficientes das elasticidades são os mesmos para todos os regimes, enquanto os N/A no modelo dos bens de capital sinaliza que este foi estimado com apenas dois regimes.

Tabela 4

Modelos Markovianos de Alternância de Regime

\begin{tabular}{|c|c|c|c|c|c|c|}
\hline & \multicolumn{3}{|c|}{ Elasticidade Câmbio } & \multicolumn{3}{|c|}{ Elasticidade Renda } \\
\hline & Regime 0 & Regime 1 & Regime 2 & Regime 0 & Regime 1 & Regime 2 \\
\hline M & $-0.55^{* * *}$ & - & - & $1.55^{* * *}$ & $1.50^{* * *}$ & $1.43^{* * *}$ \\
\hline$B C D$ & $-0.51^{* * *}$ & $-1.68^{* * *}$ & $-2.00^{* * *}$ & $6.46^{* * *}$ & $0.93^{*}$ & -0.48 \\
\hline BCND & 0.01 & $0.34^{* * *}$ & $0.44^{* *}$ & $1.93^{* * *}$ & $2.33^{* * *}$ & $2.00^{* * *}$ \\
\hline $\mathrm{BI}$ & $-0.15^{* * *}$ & - & - & $1.98^{* * *}$ & $1.97^{* * *}$ & $1.90^{* * *}$ \\
\hline BK & $-0.85^{* * *}$ & $-0.38^{* * *}$ & N/A & 0.74 & $3.40^{* * *}$ & N/A \\
\hline C\&L & 0.11 & - & - & -0.21 & - & - \\
\hline Serv. TRA & $-0.32^{* *}$ & 0.00 & $-0.10^{*}$ & $4.52^{* * *}$ & - & - \\
\hline Serv. Outros & $-1.10^{* * *}$ & - & - & $3.10^{* * *}$ & - & - \\
\hline
\end{tabular}

*** rejeita $\mathrm{H} 0$ a $1 \%$; ** rejeita $\mathrm{H} 0$ a $5 \%$; * rejeita $\mathrm{H} 0$ a $10 \%$.

Os resultados da Tabela 4 corroboram e estendem os resultados dos testes de cointegração. Mais uma vez temos a baixa elasticidade-preço das importações agregadas e a demanda interna com elasticidades altas que variam pouco entre os regimes. Os $B C D$ permanecem bastante sensíveis ao câmbio, principalmente nos regimes 1 e 2 em que a renda e as importações de BCD estão estagnadas, do início da amostra até 2003 T2 e de 2012 T1 até o final. Mais uma vez a elasticidade-preço dos $B C N D$ é positiva e diferente de zero nos regimes 1 e 2 .

As importações de $B K$ também exibem o mesmo comportamento identificado na análise de cointegração com uma queda - em termos absolutos - do coeficiente do câmbio de -0.85 para -0.38 e aumento da renda de 0.74 para 3.4 no regime 1 que se estende de 2002 T4 até 2013 T2. E mais uma vez temos Serv. Outros bastante sensíveis e Serv.TRA insensíveis ao câmbio real.

(22 As siglas são para Markov Switching em I (intercepto), M (médias) e H (heterocedasticidade). Ver Krolzig (1998).

(23) Foram selecionados os modelos com menor raiz do erro quadrático médio (RMSE) e erro percentual médio (MAPE), dentre os modelos estimados que não apresentaram problemas nos resíduos pelo testes de de Portmanteau, de Normalidade e ARCH-LM. 
Já os bens intermediários apresentam uma elasticidade-preço muito baixa, de -0.15 , e elasticidade-renda próxima de 2 . Contribuem, assim, decisivamente para a insensibilidade das importações agregadas à taxa de câmbio. Também como esperado, as importações de $C \& L$ guardam pouco ou nenhuma relação com as variáveis explicativas.

Por fim, foram estimados oito VARs, um para cada uma das especificações das importações, com o objetivo de verificar a presença de um viés de endogeneidade. Como já afirmamos o teste tradicional de exogeneidade depende da hipótese de constância paramétrica que não é garantida na presença de quebras estruturais. Portanto, optou-se por verificar a importância do viés de endogeneidade pela observação dar funções impulso resposta a partir de diferentes hipóteses de identificação dos VARs.

Foi possível obter um VAR congruente para cada uma das especificações por meio da adição de dummies, geralmente nos períodos onde foram identificadas quebras estruturais $^{24}$. As diferentes identificações não causaram grandes variações nas funções de impulso resposta - cujos sinais foram todos compatíveis com os dos modelos apresentados acima - sugerindo que os resultados qualitativos das especificações apresentadas nessa seção não foram determinados pelo viés de endogeneidade ${ }^{25}$.

\section{Considerações finais}

As estimativas apresentadas da seção 4 corroboram a hipótese central deste artigo de que a elasticidade-preço das importações é baixa no Brasil porque a composição das importações brasileiras é fortemente concentrada em bens intermediários, combustíveis e lubrificantes e serviços de transportes e pagamentos de royalties e aluguéis de equipamentos (BI, C\&L e ServTRA) - setores nos quais os bens importados não são facilmente substituídos por outros produzidos domesticamente e que respondem por cerca de dois terços das importações totais.

Com efeito, todas as especificações econométricas apresentadas neste texto para as importações de $B I, C \& L$ e $\operatorname{ServTRA}$ foram unânimes em apontar baixas elasticidades-preço. Adicionalmente, todas as especificações econométricas para as importações de bens de capital, bens de consumo duráveis e outros serviços $(B K$, $B C D$ e ServOutros) reportadas indicaram elasticidades-preço bem mais elevadas do que as verificadas para as importações de $B I, C \& L, \operatorname{ServTRA}$ e para as importações

(24) Apesar de pouco usual hoje em dia o uso de dummies para captar efeito de mudanças significativas ou choques exógenos em um VAR não é incomum na literatura macroeconômica aplicada como em Blanchard e Perotti (1999), Ramey e Shapiro (1998).

(25) Por motivos de espaço não apresentaremos os resultados dos VARs nesse texto. Os leitores interessados podem obtê-los, entretanto, por meio de contato com os autores. 
agregadas. Ocorre que as importações de $B K, B C D$ e Serv. Outros juntas não ultrapassam $30 \%$ do total, ou pouco mais de um terço do total caso sejam adicionadas das importações de bens de consumo não duráveis - cujos resultados, talvez surpreendentemente, também indicam uma elasticidade-preço baixa.

Naturalmente, mais estudos - setoriais, em alguns casos - são necessários para se estabelecer a causa precisa e a robustez do resultado da baixa substitutibilidade entre os bens domésticos e importados nos casos dos setores de bens intermediários e de bens de consumo não duráveis em particular.

De todo modo, os resultados apresentados neste trabalho sugerem fortemente que a pauta de importações brasileiras vem se enrijecendo desde os anos 1990 e que este problema é estrutural e, portanto, dificilmente poderá ser corrigido no curto prazo de alguns trimestres ou mesmo anos.

\section{Referências bibliográficas}

BASTOS, V. D.; COSTA, L. M. Déficit comercial, exportações e perspectivas da indústria química brasileira. Rio de Janeiro: Banco Nacional de Desenvolvimento Econômico e Social, 2011. p. 163-206. (BNDES Setorial, n. 33).

BLANCHARD, O.; PEROTTI, R. An empirical characterization of the dynamic effects of changes in government spending and taxes on output. Cambridge, MA: National Bureau of Economic Research, 1999. (NBER Working Papers, n. 7269).

BRESSER-PEREIRA, L. C. A taxa de câmbio no centro da teoria do desenvolvimento. Estudos Avançados, v. 26, n. 75, p. 7-28, 2012.

BUENO, R. D. L. S. Econometria de Séries Temporais. São Paulo: Cengage Learning, 2008.

CARVAlHO, A.; PARENTE, M. A. Estimação de equações de demanda de importação por categoria de uso no Brasil (1978/1996). Brasília: Instituto de Pesquisa Econômica Aplicada, 1999. (Texto para Discussão, n. 636).

CASTRO, Alexandre Samy de; CAVALCANTI, Marco Antônio F. H. Estimação de exportação e importação para o Brasil - 1955/95. Rio de Janeiro: Instituto de Pesquisa Econômica Aplicada, 1997. (Texto para Discussão, n. 469).

CAVALCANTI, M. A. F.H.; FRISCHTAK, C. R. Crescimento econômico, balança comercial e a relação câmbio-investimento. Rio de Janeiro: Instituto de Pesquisa Econômica Aplicada, 2001. (Texto para Discussão, n. 821).

COOK, S. Spurious rejection by cointegration tests incorporating structural change in the cointegrating relationship. Applied Economics Letters, n. 11, p. 879-884, 2004. 
DE NEGRI, J. A. A cadeia global de valor da indústria automobilística no Brasil. In: PROSCHNIK, V. (Coord.). La inserción de América Latina en las cadenas globales de valor. Montevideo: Red Mercosur de Investigaciones Económicas, 2010.

DOS SANTOS, C. H. Notas sobre as dinâmicas relacionadas do consumo das famílias, da formação bruta de capital fixo e das finanças públicas brasileiras no período 2004-2012. In: PETRELLI, V (Org.). Padrão de acumulação e desenvolvimento brasileiro. São Paulo: Editora Fundação Perseu Abramo, 2013.

ENGLE, R.; GRANGER, C. W. J. Co-integration and error correction: representation, estimation and testing. Econometrica, v. 55, n. 2, p. 251-267, 1987.

FAVERO, C. Applied macroeconometrics. Oxford: Oxford University Press, 2001.

GEREFFI, G.; HUMPHREY, J.; STURGEON, T. The governance of global value chains. Review of International Political Economy, v. 12, n. 1, p. 78-104, 2005.

GOUVEA, R; SCHETTINI, B. Estimativas econométricas para as importações agregadas com dados das contas nacionais trimestrais - 1996-2010. Brasília: Instituto de Pesquisa Econômica Aplicada, 2011. (Texto para Discussão, n.1683).

GREGORY, A. W.; HANSEN, B. E. Residual-based tests for cointegration in models with regime shifts. Journal of Econometrics, v. 70, p. 99-126, 1996.

HAMILTON, J. D. A new approach to the economic analysis of nonstationary time series and the business cycle. Econometrica: Journal of the Econometric Society, p. 357-384, 1989.

HAMILTON, J. D. Time series analysis. Princeton: Princeton University Press, 1994.

HENDRY, D. F. Dynamic econometrics. Oxford: Oxford University Press, 1995.

JOHANSEN, S. Statistical analysis of cointegration vectors. Journal of Economic Dynamics and Control, v. 12, p. 231-254, 1988.

JOHANSEN, S. Estimation and hypothesis testing of cointegration vectors in Gaussian vector autoregressive models. Econometrica, v. 59, p. 1551-1580, 1991.

JUSELIUS, K. The cointegrated VAR model. Oxford: Oxford University Press, 2006.

LEE, J.; STRAZICICH, M. C. Minimum LM unit root test with two structural breaks. Review of Economics and Statistics, v. 63, p.1082-1089, 2003.

LEYBOURNE, S.; NEWBOLD, P. Spurious rejections by cointegration tests induced by structural breaks. Applied Economics, v. 35, p. 1117-1121, 2003.

LÜTKEPOHL, Helmut; MARKUS, Krätzig, (Ed.). Applied time series econometrics. Cambridge: Cambridge University Press, 2004. 
MINELLA, A.; SOUZA-SOBRINHO, N. Canais monetários no Brasil sob a ótica de um modelo semiestrutural. In: BANCO Central do Brasil. Dez anos de metas para a inflação - 1999-2009. Brasília: Banco Central do Brasil, 2011.

MUINHOS, M. K.; ALVES, S. A. L. Medium-size macroeconomic model for the Brazilian economy. Brasília: Banco Central do Brasil, 2003. (Working Paper Series, n. 64).

OREIRO, J. L.; FEIJÓ, C. A. Desindustrialização: conceituação, causas, efeitos eo caso brasileiro. Revista de Economia Política, v. 30, n. 2, p. 219-232, 2010.

PORTUGAL, M. S. Um modelo de correção de erros para a demanda por importações brasileiras. Pesquisa e Planejamento Econômico, v. 22, n. 3, 1992.

RAMEY, V. A.; SHAPIRO, M. D. Costly capital reallocation and the effects of government spending. Carnegie-Rochester Conference Series on Public Policy, North-Holland, v. 48, p. 145-194, Jun. 1998.

REIS, E. R. et al. Model for projections and simulations of the Brazilian economy. Rio de Janeiro: Instituto de Pesquisa Econômica Aplicada, 1999. (Texto para Discussão, n. 619).

RESENDE, M. F. C. Crescimento econômico, disponibilidade de divisas e importações no Brasil: um modelo de correção de erros. Pesquisa e Planejamento Econômico, v. 31, n. 2, p. 289-330, 2001.

SAPIENZA, L. D. Análise do desempenho da balança comercial brasileira Estimações das elasticidades das funções de oferta de exportação e demanda de importação (1980/2006). Dissertação (Mestrado)-Escola de Economia de São Paulo da Fundação Getúlio Vargas, 2007.

SARTI, F.; HIRATUKA, C. (Coord.). Perspectivas do investimento no Brasil. v. 2: Perspectivas do investimento na indústria. Rio de Janeiro: Synergia, Instituto de Economia da UFRJ; Campinas: Unicamp. Instituto de Economia, 2010.

SIMS, C.; STOCK, J.; WATSON, M. Inference in linear time series models with some unit roots. Econometrica, v. 58, n. 1, p. 113-144, Jan. 1990.

TAVARES, M. D. C. Auge e declínio do processo de substituição de importações no Brasil. In: TAVARES, M. D. C. Da substituição de importações ao capitalismo financeiro. Rio de Janeiro: Zahar Editores, 1972. p. 27-124.

ZINI JR., A. A. Funções de exportação e de importação para o Brasil. Pesquisa e Planejamento Econômico, v. 18, n. 3, p. 615-662, 1988.

ZIVOT, E.; ANDREWS, D. W. K. Further evidence on the great crash, the oil price shock and the unit root hypothesis. Journal of Business and Economic Statistics, v. 10, p. 251-270, 1992. 